\title{
Bacterial colonization of medical equipments: A surveillance study of NICU and PICU instruments
}

\author{
Kandwal P. ${ }^{1}$, Roy R. ${ }^{2}$, Rana S. K. ${ }^{3}$, Mahawal B. S. ${ }^{4}$ \\ ${ }^{1}$ Priya Kandwal, Lecturer, Department of Microbiology, Uttaranchal Dental and Medical Research Institute, Dehradun, \\ Uttarakhand, India, ${ }^{2}$ Dr. Reshmi Roy, Assistant Professor, Department of Microbiology, Sri Guru Ram Rai Institute of Health \\ and Medical Sciences, Dehradun, Uttarakhand, India, ${ }^{3}$ Dr. Sudhir K Rana, Professor, Department of Paediatrics, Sri Guru Ram \\ Rai Institute of Health and Medical Sciences, Dehradun, Uttarakhand, India, ${ }^{4}$ Dr. Bhim S. Mahawal, Professor \& Head, \\ Department of Microbiology, Lumbini Medical College, Palpa, Nepal.
}

Corresponding Author: Dr. Reshmi Roy, Assistant Professor, Department of Microbiology, Sri Guru Ram Rai Institute of Health and Medical Sciences, Dehradun, Uttarakhand India. Email: reshmichanda@gmail.com.

\begin{abstract}
Introduction: Health care associated infection in intensive care unit is a challenging issue worldwide. Fomites and inanimate objects/ equipment may be contaminated by various pathogenic microorganisms by the health care worker. Therefore, could be potential risk factor for the critical ill patients of neonatal and pediatric intensive care units (NICUs \& PICUs). The present study was carried out to examine the bacterial colonization from equipments of pediatric and neonatal ICUs. Materials and methods: A total of 260 specimens were collected within a period of six months from the instruments/hands and nasal swabs of health care workers using moisten $(0.9 \% \mathrm{w} / \mathrm{v}$ physiological saline $)$ sterile cotton swab. Samples were processed according to standard protocol. Result: In the current study, the most prevalent organism on the surface of medical devices of PICU were CoNS $(16.66 \%)$ and $S$. aureus (16.66\%) while in NICU the most prevalent organism was Klebsiella spp (11.25\%) followed by A. baumanni (10\%), E.coli (2.5\%), CoNS (6.25\%), S. aureus $(6.25 \%)$ and E. faecalis $(6.25 \%)$. Conclusion: The study highlights the importance of surveillance of risk factors of hospital acquired infection and strategic implantation of preventive measures in critical care units.
\end{abstract}

Keywords: Bacterial colonization, Health care associated infection, NICU, PICU, Surveillance.

\section{Introduction}

Hospital acquired infections (HAI) are a serious problem in hospitals and responsible for increased rate of morbidity and mortality in hospitalized patients. The longer stay in hospitals significantly increases the hospital cost burden on the patients [1]. Intensive care unit patients are associated with a much greater risk of acquiring HAI than other departments [2]. Intensive care unit (ICU) staffs are the vehicles for spread of microorganisms which may be the cause of nosocomial infections of ICU patients $[2,3]$.

Microbiological surveillance is an integral part of infection control program; which provides data about contributing factor of infection [4]. Fomites which includes surfaces and inanimate objects are associated particularly $20-40 \%$ of HAI, due to the cross infection via hands of health care workers (HCWs), who have become contaminated from direct contact with patient or indirectly by touching contaminated hospital environmental surfaces.

Manuscript received: $10^{\text {th }}$ October 2019

Reviewed: $20^{\text {th }}$ October 2019

Author Corrected: $30^{\text {th }}$ October 2019

Accepted for Publication: $6^{\text {th }}$ November 2019
Therefore inanimate object/fomites serve as reservoir of pathogen from where pathogen is transferred to patient via the hands of HCW. Establishing source of infection is often a matter of significant importance in infection prevention because one may eliminate or segregate the source from the susceptible patient [2]. Unlike our hands which can be easily sterilized by hand sanitizer but most of the medical equipments are troublesome to clean or lack any standard protocol [5].

Based on the lack of epidemiological data that would guide cleaning of inanimate surfaces of immediate vicinity of patient; some literature stated cleaning with nonantimicrobial detergent, on the other hand few prefer to disinfect with antimicrobial agents based on the risk of infection due to microbial contamination and potential transmission of nosocomial pathogen. Irrespective of divergent opinions fair scientific assessment is that, the longer nosocomial pathogen persists on a surface the longer it may be a source of transmission and thus endanger susceptible patient. Many gram-negative bacteria, such as

Pathology Update: Tropical Journal of Pathology \& Microbiology Available online at: www.medresearch.in 1026|P a g e 
Acinetobacter spp., Escherichia coli, Klebsiella spp., Pseudomonas aeruginosa, Serratia marcescens, Shigella spp., can survive on inanimate surfaces even for months [6]. This surveillance study was done to focus the colonization and to highlight the importance of risk factor assessment of intensive care units.

\section{Material and Methods}

Study area and duration of study: The present work has been performed in the Department of Microbiology, Bacteriology Section of the Shri Guru Ram Rai Institute of Medical and Health Science, Patel Nagar, Dehradun from September 2015 to February 2016. Samples were collected from NICU \& PICU.

Study type: Cross-sectional study.

Sampling method: For the purpose of this study, samples were collected through purposive sampling method.

Specimen collection: Specimens were collected from the surface of the instruments using moisten $(0.9 \% \mathrm{w} / \mathrm{v}$ physiological saline) sterile cotton swabs. Similarly, nasal and hand swabs were also taken from health care workers.

\section{Sample size and processing}

A total of 260 samples were considered for bacterial examination, 80 from different equipments, 30 nasal swabs and 30 hand swabs from NICU. Similarly, 60 swabs from different equipments, 30 nasal swabs and 30 hand swabs from PICU. Immediately the samples were brought to the department of Microbiology, Bacteriology section.

The samples were plated on Blood agar, MaCconkey agar and incubated at $37^{\circ} \mathrm{C}$ for 24 hours. Second day on the basis of gram stain, biochemical tests were put and antibiotic susceptibility (Kirby-Bauer disc diffusion) test was performed. Plates were incubated at $37^{\circ} \mathrm{C}$ in an aerobic environment for 24 hours.

The results of antibiotic sensitivity were interpreted on the basis of diameter of growth inhibition zone according to CLSI guidelines. Identification of organisms were done on the basis of standard protocol $[7,8,9]$.

\section{Result}

Table-1: Spectrum of micro-organism isolated from medical devices in PICU

\begin{tabular}{|l|c|c|c|c|c|c|c|}
\hline N= 60 (PICU) & CONS & $\begin{array}{c}\text { S. } \\
\text { aureus }\end{array}$ & $\begin{array}{c}A \\
\text { baumanii }\end{array}$ & $\begin{array}{c}\text { Candida } \\
\text { spp }\end{array}$ & Micrococcus & Bacillus & $\begin{array}{c}\text { No } \\
\text { growth }\end{array}$ \\
\hline Bed (n=8) & 2 & 1 & --- & 1 & --- & 2 & 2 \\
\hline Monitor (n=6) & 3 & 1 & 2 & --- & 1 & 1 & 2 \\
\hline Infusion pump (n=2) & --- & --- & --- & --- & --- & --- & 2 \\
\hline $\begin{array}{l}\text { Radiant heat warmer } \\
(\mathrm{n}=8)\end{array}$ & --- & 2 & --- & --- & 1 & 5 \\
\hline $\begin{array}{l}\text { Weighing machine } \\
(\mathrm{n}=6)\end{array}$ & 2 & 1 & 2 & --- & --- & --- & 1 \\
\hline IV stand (n=6) & --- & 2 & --- & --- & 2 & --- & 2 \\
\hline X- ray machine (n=6) & 1 & 2 & --- & --- & --- & --- & 3 \\
\hline Tubings (n=7) & 1 & --- & 1 & 1 & 2 & --- & 2 \\
\hline Ventillator (n=7) & 1 & 1 & 1 & --- & --- & 2 & 2 \\
\hline Total (\%) & $\mathbf{1 0}$ & $\mathbf{1 0}$ & $\mathbf{6}$ & $\mathbf{2}$ & $\mathbf{6}$ & $\mathbf{5}$ & $\mathbf{2 1}$ \\
\hline
\end{tabular}

Table 1 signifying different organisms isolated from different instruments of PICU. ' $n$ ' corresponded total number of times samples were taken.

Table-2: Hand carriage of microorganisms in Health care workers of PICU

\begin{tabular}{|c|c|c|c|c|c|}
\hline Hand swab & CONS & S.aureus & Micrococcus & Bacillus & No growth \\
\hline$(\mathrm{n}=30)$ & 12 & 6 & 2 & 4 & 6 \\
& $(\mathrm{MRCONS}=3) 40 \%$ & $(\mathrm{MRSA}=1) 20 \%$ & $6.66 \%$ & $13.3 \%$ & $20 \%$ \\
\hline
\end{tabular}

Table 2 highlighting organisms isolated from swabs taken from the hands of health care workers of PICU. 
Table-3: Nasal carriage of microorganism in Health care workers of PICU

\begin{tabular}{|c|c|c|c|c|}
\hline Nasal swab & CONS & S.aureus & Micrococcus & No growth \\
\hline \multirow{3}{*}{$(\mathrm{n}=30)$} & 15 & 8 & 5 & 2 \\
& $(\mathrm{MRCoNS}=3)$ & $(\mathrm{MRSA}=3)$ & $16.66 \%$ & $6.66 \%$ \\
\hline
\end{tabular}

Table 3 signifying different organisms isolated from swabs taken from the external nares of health care workers.

Table-4: Organism isolated from various site of medical instruments in NICU

\begin{tabular}{|c|c|c|c|c|c|c|c|c|}
\hline $\begin{array}{l}\text { Total no of samples } \\
\qquad(\mathrm{n}=\mathbf{8 0})\end{array}$ & 窇 & 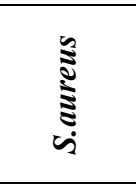 & 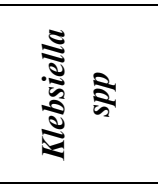 & 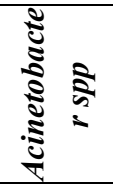 & 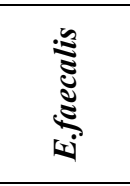 & 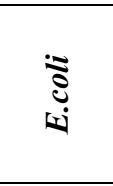 & 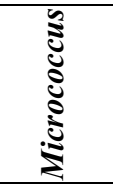 & $\begin{array}{l}0 \\
0 \\
0 \\
0 \\
0 \\
0\end{array}$ \\
\hline Weighing machine $(n=8)$ & -- & 1 & 2 & 1 & 1 & -- & 1 & 2 \\
\hline $\begin{array}{l}\text { Phototherapy machine } \\
(n=8)\end{array}$ & 3 & -- & -- & -- & -- & 1 & 3 & 1 \\
\hline Radiant heat warmer $(\mathrm{n}=8)$ & -- & 2 & -- & 2 & 1 & -- & 2 & 1 \\
\hline Monitor $(\mathrm{n}=8)$ & -- & -- & -- & -- & -- & -- & 1 & 7 \\
\hline Oxygen hood $(\mathrm{n}=8)$ & -- & 2 & -- & -- & 1 & -- & 1 & 4 \\
\hline Suction machine $(\mathrm{n}=8)$ & 1 & -- & 2 & -- & -- & 1 & 2 & 2 \\
\hline Syringe pump $(\mathrm{n}=8)$ & -- & -- & -- & 1 & 1 & -- & 2 & 4 \\
\hline Bed with mattress $(n=8)$ & -- & -- & -- & 1 & -- & -- & 3 & 4 \\
\hline Nasal cannula $(\mathrm{n}=8)$ & 1 & -- & 2 & -- & -- & -- & -- & 5 \\
\hline Ventillator $(n=8)$ & -- & -- & 3 & 3 & 1 & -- & 1 & 0 \\
\hline Total & $\begin{array}{c}5 \\
(6.25 \%)\end{array}$ & $\begin{array}{c}5 \\
(6.25 \%)\end{array}$ & $\begin{array}{c}9 \\
(11.25 \%)\end{array}$ & $\begin{array}{c}8 \\
(10 \%)\end{array}$ & $\begin{array}{c}5 \\
(6.25 \%)\end{array}$ & $\begin{array}{c}2 \\
(2.5 \%)\end{array}$ & $\begin{array}{c}16 \\
(20 \%)\end{array}$ & $\begin{array}{c}30 \\
(37.5 \%)\end{array}$ \\
\hline
\end{tabular}

Table: 4 signifying different organisms isolated from different instruments of NICU. ' $n$ ' corresponded total number of times samples were taken.

Table-5: Nasal carriage of microorganism of health care workers of NICU

\begin{tabular}{|c|c|c|c|c|}
\hline Nasal swab & CONS & S.aureus & Micrococcus & No growth \\
\hline$(\mathrm{n}=30)$ & $13(\mathrm{MRSA}=3)$ & $7(\mathrm{MRSA}=2)$ & 6 & 4 \\
& $43.33 \%$ & $23.33 \%$ & $20 \%$ & $13.33 \%$ \\
\hline
\end{tabular}

Table 5 representing organisms isolated from swabs taken from the external nares of health care workers of NICU.

Table-6: Hand carriage of microorganism of health care workers of NICU

\begin{tabular}{|c|c|c|c|c|c|c|}
\hline Hand swab & CONS & S.aureus & Acinetobacter & K. pneumoniae & Bacillus & No growth \\
\hline$(\mathrm{n}=30)$ & $4(\mathrm{MRSA}=1)$ & $5(\mathrm{MRSA}=2)$ & 5 & 4 & 7 & 5 \\
& $13.33 \%$ & $16.66 \%$ & $16.66 \%$ & $13.33 \%$ & $23.33 \%$ & $16.66 \%$ \\
\hline
\end{tabular}

Table 6 representing organisms isolated from swabs taken from the hands of health care workers of NICU.

\section{Discussion}

Patient admitted in ICUs are at higher risk of developing HCAI due to severity of the underlying illness, increased utilization of invasive medical devices. Surveillance is an essential element so as to know the current prevalence of the condition, to identify potential risk factors and to implement various preventive strategies [10]. Contamination of inanimate surfaces in ICU has been identified in outbreaks and cross-transmission of pathogens among critically ill patients. Contamination may occur either by transfer of microorganisms containing health worker's hand or direct patient shedding of microorganisms in immediate environment of patient's bed [11]. Majority of health care associated infection may be prevented by evidence-based interventions; and one such intervention is decolonization which can minimize the rate of hospital acquired infection. Decolonization can prevent both 
horizontal and vertical transmission depending on the methods [12]. It is the duty of healthcare professional to take role in infection control and to maintain personal hygiene by using mask, gloves, head covers or proper uniform wherever necessary for healthcare delivery [13].

In the current study, the most prevalent organism on the surface of medical devices in PICU were CoNS (16.66\%) and S.aureus (16.66\%) (Table:1) while in NICU the most prevalent organism was Klebsiella spp (11.25\%) among Enterobacteriaceae group followed by A. baumani (10\%), E.coli (2.5\%), CoNS (6.25\%), S. aureus (6.25\%)and E. faecalis (6.25\%) (Table:4). Similar to this result, another study on environment surface of hospital wards showed that CoNS and Klebsiella spp as predominant isolates and was the most prevalent isolated bacteria [14,1]. A.D. Khosravi et al. have shown Staphylococcus as the commonest organism isolated from hospital environment followed by Pseudomonas aeruginosa and Klebsiella ozaenae [15].

It has been reported in various studies that both gram positive and gram-negative bacteria are able to survive up to months on dry inanimate surfaces, with longer persistence under humid and lower temperature condition. During outbreaks environment play significant role in transmission HAI $[16,11]$. Due to various clinical factors as well as life threatening factors the critical ill patients of ICU of neonate and pediatric requires high clinical care and attention. At the point of care contamination occurs via cross transmission from medical equipment, clothing and colonized /infected health care worker/patient [17].

In the present study it has been seen that colonized organisms of health care worker are matching with the organisms present on the equipments. Infections caused by multidrug-resistant (MDR) bacteria are a worrisome healthcare problem and it is a daily challenge for the clinician dealing with critically ill patients [15]. In the present study MRSA and MRCoNS found in colonization with normal microbial flora of health care workers (Table $2,3,5,6)$ of NICU and PICU.

Organisms isolated from equipments of PICU (MRCoNS 4 out of 10; MRSA 3 out of 10) and NICU (MRCoNS 2 out of 5; MRSA 2 out of 5) have also shown to colonized with resistant bacteria. Various studies also stated the transmission of multi drug resistant pathogens like MRSA, ESBL, multiresistant Acinetobacter baumanii in neonatal ICUs [18]. As bacteria are the part of human microflora of the body; between 15 to $30 \%$ of healthy adults are nasally colonized with methicillin susceptible $S$. aureus and 1 to $3 \%$ methicillin resistant $S$. aureus [12]. Hands of healthcare worker have a key role in environmental contamination, along with direct patient shedding. Inanimate surface contamination provides a reservoir for patient cross- transmission of bacteria and may contribute to patient's colonization and in some circumstance's infection $[11,13,19]$. High level of contamination indicates needs of periodic surveillance for early detection of bacterial colonization [19]. Perhaps there is lack of disinfection guidelines or difficult to clean items/equipments; the contribution of these items in health care associated infection should not be overlooked/ forgotten.

The environmental contamination pose an even a greater challenge in the neonatal and pediatric ICU where patients are naturally immunosuppressive with critical ill condition with several risk factors for nosocomial infection and highest standard measures of prevention cannot always be addressed due to impelling life threatening condition [20]. Therefore, to minimize ICU-acquired colonization and infection there is necessity of strict compliance of adherence of hand hygiene guidelines.

\section{Conclusion}

Due to noncompliance to the guidelines of the hand wash of the heath care workers, the contamination of inanimate object also needs to be considered as source of infection of critically ill patients. Therefore, mandate periodic awareness of either the use of hand wash or decontamination of inanimate object need to be implemented.

\section{What the study adds to the existing knowledge?}

To conclude the present study highlights the periodic surveillance of environmental/surface/ inanimate object of ICU to monitor colonization status and also strongly consider adherence of hand hygiene guidelines.

\section{Author's contribution}

Dr. Reshmi Roy: Principal Investigator

Priya Kandwal: Helped with data collection and preparation of outline of the project

Dr. Sudhir K Rana: Guidance and proof reading

Dr. Bhim S Mahawal: Guidance and proof reading

Funding: No funding sources

Conflict of interest: None declared

Ethical Approval: This study was approved by the Institutional Ethics Committee

\section{References}

1. Singh S, Pandya Y, Pate Rl, Paliwal M, Wilson A, Trivedi S. Surveillance of device-associated infections at a teaching hospital in rural Gujarat - India. Indian J Med Microbiol. 2010;28(4):342-347. doi: 10.4103/0255-0857. 71830 . 
2. Amer C, Jasmina S, Sadeta H, Sead A, Nijaz T, Haris H. Epidemiological Surveillance of Bacteria Nosocomial Infections in the Surgical Intensive Care Unit. Mater Sociomed. 2014;26(1):7-11.

3. Tajeddin E, Rashidana M, Razaghia M, Javadia S.S, Sherafata S. J, Alebouyeha M, Mohammad R. Sarbazic, Mansourid N, Zali M. R. The role of the intensive care unit environment and health-care workers in the transmission of bacteria associated with hospital acquired infections. J Infect Pub Health. 2016;(9):13-23. doi.org/10.1016/j.jiph. 2015. 05.010 .

4. Yadav M, Pal R, Sharma SH, Khumanthem SD. Microbiological surveillance of operation theatre in a tertiary care hospital in North East India. Int J Res Med Sci. 2017; 5(8): 3448-3453. doi: http://dx.doi. org/10.18203/ 2320-6012. ijrms20173538.

5. Haghbin S, Pourabbas B, Serati Z, and Alborzi A. Bacterial Contamination of Mobile Phones and Pens in Pediatric and Neonatal Intensive Care Units. Int J Curr Microbiol App Sci. 2015;4(2):75-81.

6. Kramer A, Schwebke I and Kampf G. How long do nosocomial pathogens persist on inanimate surfaces? A systematic review. BMC Infectious Dis. 2006;130(6):1-8. doi:10.1186/1471-2334-6-130.

7. Patricia M. Tille. Bailey and Scott's Diagnostic Microbiology. $13^{\text {th }}$ edition. Elsvier; 2018.

8. Koneman EW, Allen SD, Janda WM, Schreckenberger PC, Winn, Jr. WC. Color atlas and textbook of diagnostic microbiology $6^{\text {th }}$ ed. Lippincot, Philadelphia, 2006.

9. Collee J G, Fraser A G, Marmion B P, Simmons A. Mackie and McCartney Practical Medical Microbiology. $14^{\text {th }}$ Ed. Churchill Livingstone: Elsvier; 2012.

10. Agarwal R, Mohapatra S, Prasad Rath G, Kapil A. Active Surveillance of Health Care Associated Infections in Neurosurgical Patients. J Clinic Diagnos Res. 2017; 11 (7): 1-4. doi: 10.7860/JCDR/2017/26681.10146.

11. Vincenzo R, Andrea C, Teresa F, Pasquale I, Santi M R, Cesare G et al. What Healthcare Workers Should Know about Environmental Bacterial Contamination in the Intensive Care Unit. BioMed Res Int. 2017; 1- 7. doi.org/ $10.1155 / 2017 / 6905450$.
12. Septimus EJ, Schweizer ML. Decolonization in prevention of health care-associated infections. Clin Microbiol Rev. 2016; 29: 201-222. doi:10.1128/CMR. 00049-15.

13. Khan HA, Baig FK, Riffat Mehboob R. Nosocomial infections: Epidemiology, prevention, control and surveillance. Asian Pac J Trop Biomed. 2017;7(5):478-482. doi: dx.doi.org/10.1016/j.apjtb.2017.01.019.

14. Ekrami AR, Kayedani A, Jahangir M, Kalantar E, Jalali M. Isolation of common aerobic bacterial pathogens from the environment of seven hospitals, Ahvaz, Iran. Jundishapur J Microbiol. 2011; 4 (2):75-82.

15. Khosravi AD, Ahmadi F, Salmanzazdeh S, Dashtbozorg A, Montazeri AE. Study of bacteria isolated from orthopedic implant infections and their Antimicrobial Susceptibility Pattern. Res J Microbiol.2009;4(4):158-163. doi: 10.3923/jm.2009.158.163.

16. Yusuf J B, Okwong O K, Mohammed A, Abubakar K, Babayo A, Barma M M et al. Bacterial Contamination of Intensive Care Units at a Tertiary Hospital in Bauchi, Northeastern Nigeria. Am J Int Med. 2017; 5(3): 46-51.

17. Bhattacharya S and Mondal AS. Clinical microbiology in the intensive care unit: Strategic and operational characteristics. Indian J Med Microbiol. 2010;28(1):5-10. doi: 10.4103/0255-0857.58720.

18. Mehta Y, Gupta A, Todi S, Myatra SN, Samaddar DP, Patil V, Bhattacharya PK and Ramasubban S. Guidelines for prevention of hospital acquired infections. Indian J Crit Care Med. 2014;18(3):149-163. doi: 10.4103/09725229.128705: 10.4103/0972-5229.128705.

19. Kiranmai S, Madhavi K. Microbiological surveillance of operation theatres, intensive care units and labor room of a teaching hospital in Telangana, India. Int J Res Med Sci. 2016;4(12):5256-5260.

20. Vincenzo R, Andrea C, Santi M R and Antonino G. Bacterial contamination of inanimate surfaces and equipment in the intensive care unit. J Intens Care. 2015; 3:54. doi 10.1186/s40560-015-0120-5.

\section{How to cite this article?}

Kandwal P, Roy R, Rana S. K, Mahawal B. S. Bacterial colonization of medical equipments : A surveillance study of NICU and PICU instruments. Trop J Path Micro 2019;5(12):1026-1030.doi:10.17511/ jopm.2019.i12.10 